\title{
Comparison of the capacitation-like state of cooled boar spermatozoa with true capacitation
}

\author{
C. E. Green and P. F. Watson* \\ Department of Veterinary Basic Sciences, Royal Veterinary College, Royal College Street, \\ London NW1 OTU, UK
}

Cryopreserved spermatozoa demonstrate reduced conception rates compared with fresh spermatozoa when used for artificial insemination. The preliminary stage of cryopreservation of spermatozoa involves cooling to $5^{\circ} \mathrm{C}$, during which spermatozoa experience a capacitation-like change, which may be partially responsible for the reduced conception rate observed. The aim of this study was to determine the nature of these capacitation-like changes and how much this process resembles true capacitation. Boar spermatozoa, cooled to $5^{\circ} \mathrm{C}$ and rewarmed to physiological temperatures $\left(39^{\circ} \mathrm{C}\right)$, were compared with spermatozoa capacitated in Tyrode's complete medium (TALP) for $2 \mathrm{~h}$ at $39^{\circ} \mathrm{C}$. Fluorescent probes, and SDS-PAGE and western blotting were used to visualize events known to occur during capacitation in vitro. Chlortetracycline staining of membrane domains and Fluo-3 detection of changes in intracellular free calcium by flow cytometry in cooled and re-warmed spermatozoa showed similarities to those of capacitated spermatozoa. Alterations to lipid bilayer fluidity assessed by merocyanine fluorescence staining and intracellular signalling pathways detected by tyrosine phosphorylation of cooled and re-warmed spermatozoa, did not completely reflect the changes detected during capacitation in vitro. Thus, cooling spermatozoa to $5^{\circ} \mathrm{C}$ results in a similar endpoint to that observed in capacitated cells in terms of reactive membranes and changes in intracellular ion concentrations, which may account for their comparable functionality. However, these modifications are not completely analogous and should not be considered true capacitation, but rather a by-passing of the capacitation process.

\section{Introduction}

Optimal cryopreservation protocols for mammalian spermatozoa seem able to maintain only approximately $50 \%$ survival and it is now recognized that the surviving population of spermatozoa is compromised as a result of capacitation-like changes (Watson, 1995). These changes are also seen after cooling to $5^{\circ} \mathrm{C}$ (Fuller and Whittingham, 1996, 1997; Cormier et al., 1997). The cooled spermatozoa require no preliminary incubation to acquire fertilizing ability (Fuller and Whittingham, 1996), readily undergo an acrosome reaction (Clarke and Johnson, 1987; Gillan et al., 1999) and exhibit a shortened lifespan in the female reproductive tract. The apparent decrease in conception rates of mammals inseminated with cooled or cryopreserved spermatozoa (Watson, 1979, 1990) can be partially counteracted by inseminating a larger number of spermatozoa (Johnson, 1985), or inseminating closer to the site (boar: Polge et al., 1970; ram: Maxwell et al., 1993) or the time of ovulation (rabbit: Parrish and Foote, 1986; ram: Maxwell et al., 1993; boar: Waberski et al., 1994). However, these solutions pose problems of practicality and expense. Inseminating larger numbers of spermatozoa

*Correspondence

Email: pwatson@rvc.ac.uk results in increased costs, and the procedure of performing surgical insemination, which must be carried out by a qualified veterinary surgeon, does not lend itself to the applications of large-scale animal production.

Therefore, the aim of the present study was to gain an understanding of the mechanisms that result in the premature activation of cooled spermatozoa and to highlight processes that might be targeted to prevent, reverse or delay these changes. The effects of capacitation in vitro have been compared with the effects of cooling and re-warming, and several phenomena known to be associated with capacitation have been assessed.

\section{Materials and Methods}

\section{Media}

Sperm capacitating medium (Tyrode's complete medium, TALP; Parrish et al., 1988) consisted of $96 \mathrm{mmol} \mathrm{NaCl} \mathrm{I}^{-1}$, $3.1 \mathrm{mmol} \mathrm{KCl} \mathrm{I}^{-1}, 2.0 \mathrm{mmol} \mathrm{CaCl}_{2} \mathrm{I}^{-1}, 0.4 \mathrm{mmol} \mathrm{MgSO}_{4} \mathrm{I}^{-1}$, $0.3 \mathrm{mmol} \mathrm{NaH}_{2} \mathrm{PO}_{4} \mathrm{I}^{-1}, 10 \mu \mathrm{g}$ phenol red $\mathrm{ml}^{-1}, 20 \mathrm{mmol}$ Hepes $\mathrm{I}^{-1}(\mathrm{pH} 7.6), 5 \mathrm{mmol}$ glucose $\mathrm{I}^{-1}, 21.6 \mathrm{mmol}$ sodium lactate ${ }^{-1}, 1 \mathrm{mmol}$ sodium pyruvate $\mathrm{I}^{-1}, 15 \mathrm{mmol} \mathrm{NaHCO}_{3}$

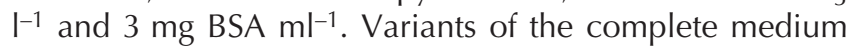
were made by omitting some or all of $\mathrm{CaCl}_{2}, \mathrm{NaHCO}_{3}$ and $\mathrm{BSA}$, depending on the requirements of the experiments. Medium prepared in the absence of all of these components 
was termed Tyrode's basal medium. Medium containing bicarbonate was equilibrated with $5 \% \mathrm{CO}_{2}$ in air. All Tyrode's media were maintained at an osmolality of 285-315 $\mathrm{mOsm} \mathrm{kg}^{-1}$ at $\mathrm{pH} 7.4$ at $39^{\circ} \mathrm{C}$. On the day of use, medium was passed through a $0.22 \mu \mathrm{m}$ filter, and pyruvate, lactate and BSA were added.

Saline medium consisted of $137 \mathrm{mmol} \mathrm{NaCl} \mathrm{I-1}, 10$ mmol glucose $\mathrm{I}^{-1}, 2.5 \mathrm{mmol} \mathrm{KOH} \mathrm{I}{ }^{-1}, 20 \mathrm{mmol}$ Hepes $\mathrm{I}^{-1}$ (buffered to $\mathrm{pH} 7.55$ with $\mathrm{NaOH}$ ), 1 mg polyvinyl alcohol (PVA) $\mathrm{ml}^{-1}$ (average $M_{\mathrm{r}} 30000-70000$ ) and $1 \mathrm{mg}$ polyvinyl pyrrolidone (PVP) $\mathrm{ml}^{-1}$ (average $M_{\mathrm{r}} 40000$ ). Sucrose medium contained $220 \mathrm{mmol}$ sucrose $\mathrm{I}^{-1}, 10 \mathrm{mmol} \mathrm{NaCl}$ $\mathrm{I}^{-1}, 2.5 \mathrm{mmol} \mathrm{KOH} \mathrm{I}-1,20 \mathrm{mmol}$ Hepes $\mathrm{I}^{-1}$ (buffered to $\mathrm{pH}$ 7.55 with $\mathrm{NaOH}$ ) and $0.5 \mathrm{mg} \mathrm{ml}^{-1}$ of both PVA and PVP (osmolality $\sim 300 \mathrm{~kg} \mathrm{ml}^{-1}$ ). PBS contained $160 \mathrm{mmol} \mathrm{NaCl}$ $\mathrm{I}^{-1}, 8 \mathrm{mmol} \mathrm{Na}_{2} \mathrm{HPO}_{4} \mathrm{I}^{-1}$ (anhydrous) and $2 \mathrm{mmol}$ $\mathrm{Na}_{2} \mathrm{HPO}_{4} \cdot \mathrm{H}_{2} \mathrm{O} \mathrm{I}^{-1}$ (osmolality approximately $300 \mathrm{~kg} \mathrm{ml} \mathrm{m}^{-1}$, $\mathrm{pH}$ 7.4). Tris-buffered saline (TBS) contained $67 \mathrm{mmol} \mathrm{NaCl}$ $\mathrm{I}^{-1}, 1$ mol Tris $\mathrm{I}^{-1}, \mathrm{pH}$ 8.0, and was supplemented with $0.05 \%$ (v/v) Tween 20 for washing of western blots.

\section{Collection and washing of semen}

Boar semen diluted and stored for $24 \mathrm{~h}$ in Beltsville thawing solution (BTS; Pursel and Johnson, 1975) was obtained from the Pig Improvement Company (PIC, Oxford). Samples of between 2 and $20 \mathrm{ml}$ semen (depending on the requirements of the experiment) containing approximately $20 \times 10^{6}$ spermatozoa $\mathrm{ml}^{-1}$ were washed. For chlortetracycline experiments, $10 \mathrm{ml}$ semen was washed by centrifugation at $600 \mathrm{~g}$ for $10 \mathrm{~min}$ and the pellet (containing approximately $200 \times 10^{6}$ spermatozoa) was resuspended and washed with a further $15 \mathrm{ml}$ PBS or $15 \mathrm{ml}$ TALP depending on the final medium required. Spermatozoa were resupended in a final volume of $500 \mu$ (approximately $400 \times 10^{6}$ spermatozoa $\mathrm{ml}^{-1}$ ). For all other experiments, spermatozoa were washed by layering them over a two step iso-osmotic Percoll gradient of $2 \mathrm{ml} \mathrm{35 \%} \mathrm{(v/v)} \mathrm{on} 2 \mathrm{ml} 70 \%$ $(\mathrm{v} / \mathrm{v})$ and centrifugation at $200 \mathrm{~g}$ for $5 \mathrm{~min}$, and then immediately at $900 \mathrm{~g}$ for a further $15 \mathrm{~min}$ (Harrison et al., 1993). Pelleted spermatozoa were gently resupended in the $70 \%$ Percoll. Washing of spermatozoa by centrifugation through Percoll was adopted in the later experiments as it 'cushions' cells when pelleted, providing a less harsh method of washing. Several chlortetracycline experiments were tested with spermatozoa that had been washed through Percoll to ensure that comparable chlortetracycline staining patterns were obtained (data not shown). Sperm concentrations were measured before (in BTS) and after (in Percoll) washing using a haemocytometer. All experiments were carried out on ejaculates from eight individual boars chosen at random.

\section{Cooling and incubation of semen}

The cooling regimen for all experiments was standard, unless otherwise stated. Boar spermatozoa were cooled from $23^{\circ} \mathrm{C}$ (room temperature) to $5^{\circ} \mathrm{C}$ over $100 \mathrm{~min}$ at a linear cooling rate of $0.18^{\circ} \mathrm{C} \mathrm{min}^{-1}$ using a computercontrolled waterbath ('cooling'). All cooled samples were incubated immediately at $39^{\circ} \mathrm{C}$ for $10 \mathrm{~min}$ ('re-warming') unless otherwise stated. All samples capacitated in vitro for comparison with cooled and re-warmed samples were incubated for $2 \mathrm{~h}$ at $39^{\circ} \mathrm{C}$ in TALP ('incubated') unless otherwise specified.

\section{Flow cytometry}

Analyses were carried out on a Coulter EPICS XL flow cytometer (Beckman Coulter Ltd, Luton) equipped with an argon laser set at $15 \mathrm{~mW}$. Sperm cells were 'gated' on forward and side scatter distributions, collected in linear mode. Subdivisions of this population were used to measure light fluorescence data, displayed in logarithmic mode. Five thousand events were collected per sample at a rate of 150-250 events per second. All fluorescent stains for flow cytometry were supplied by Molecular Probes (Eugene, OR).

\section{Capacitation status assessed by chlortetracycline/Hoechst staining assay}

Chlortetracycline (Sigma, Poole) staining was used to determine sperm cell maturational status (Ward and Storey, 1984), and membrane changes were detected in spermatozoa cooled and re-warmed in PBS in comparison with spermatozoa incubated in TALP or PBS at $39^{\circ} \mathrm{C}$ over $3 \mathrm{~h}$ (control samples were taken at hourly intervals). Treated spermatozoa were stained with chlortetracycline and Hoechst 33258 (Sigma). Five microlitres of Hoechst working solution $\left(200 \mu \mathrm{mol} \mathrm{I}^{-1}\right)$ was added to $100 \mu \mathrm{l}$ of each sperm sample $\left(\sim 400 \times 10^{6}\right.$ spermatozoa $\left.\mathrm{ml}^{-1}\right)$ and incubated for $15 \mathrm{~min}$ at ambient temperatures in the dark. Forty-five microlitres were then mixed with equal volumes of chlortetracycline solution $\left(805 \mu \mathrm{mol}\right.$ chlortetracycline $\mathrm{I}^{-1}$ and $5 \mathrm{mmol}$ cysteine $\mathrm{I}^{-1}$ in chlortetracycline buffer containing $130 \mathrm{mmol} \mathrm{NaCl} \mathrm{I}^{-1}$ and $20 \mathrm{mmol}^{\text {Tris }} \mathrm{I}^{-1}$ (Trizma base), $\mathrm{pH} 7.8)$ and fixed immediately with $8 \mu \mathrm{l}$ of $12.5 \%(\mathrm{w} / \mathrm{v})$ paraformaldehyde in $1 \mathrm{~mol}$ Tris- $\mathrm{HCl} \mathrm{I-1}, \mathrm{pH}$ 8.0. Ten microlitres of the stained and fixed solution were placed on a microscope slide and mixed with a droplet of $0.22 \mathrm{~mol}$ 1,4-diazabicyclo [2.2.2] octane $\mathrm{I}^{-1}$ (DABCO; Sigma) to prevent fading of fluorescence. Two slides were prepared per treatment sample and analysed within $1 \mathrm{~h}$ of preparation. One hundred spermatozoa were assessed per slide.

Spermatozoa exhibiting bright blue fluorescence over the entire head (under UV light) were considered as nonviable cells and chlortetracycline patterns were not recorded. Chlortetracycline staining was assessed on live spermatozoa under blue-violet illumination (excitation at 330-380 nm, emission at $420 \mathrm{~nm}$ ). Staining patterns observed were similar to those described by Wang et al. (1995), namely: F, full fluorescence (uncapacitated); B, a fluorescence-free band in the post-acrosomal domain (capacitated); and AR, low fluorescence over the entire head with a band of bright fluorescence across the equatorial segment (acrosome reacted cells). 


\section{Assessment of membrane fluidity by MC540 staining}

Changes in membrane fluidity of cooled and capacitated spermatozoa were tested using Merocyanine 540 (MC540; Harrison et al., 1996). Washed semen was diluted into Tyrode's medium at $2 \times 10^{6}$ spermatozoa $\mathrm{ml}^{-1}$ (in $1 \mathrm{ml}$ aliquots) in the presence or absence of either $15 \mathrm{mmol}$ $\mathrm{NaHCO}_{3} \mathrm{I}^{-1}$ (bicarbonate) or $3 \mathrm{mg} \mathrm{BSA} \mathrm{ml}^{-1}$, or both. All media contained $25 \mathrm{nmol}$ YO-PRO- $1 \mathrm{I}^{-1}$ (final) to stain dead cells. Samples containing bicarbonate were re-gassed over the top of the tubes before initiation of treatments. Thirtyfive microlitres of $40 \mu \mathrm{mol}$ MC540 $\mathrm{I}^{-1}$ were immediately applied to each $1 \mathrm{ml}$ treated sample $\left(0.71 \mu \mathrm{mol} \mathrm{I} \mathrm{I}^{-1}\right.$ final $)$ and incubated for $2 \mathrm{~min}$ in the dark. Spermatozoa were analysed immediately on the flow cytometer as described by Harrison et al. (1996). Treated sperm populations were categorized into low and high MC540 staining intensity or YO-PRO-1-positive non-viable cells.

\section{Measurement of intracellular calcium concentrations using Fluo-3}

Semen samples containing $20 \times 10^{6}$ spermatozoa $\mathrm{ml}^{-1}$ were loaded with the fluorescent probe Fluo-3AcetoMethoxy (AM) ester as described by Harrison et al. (1993), and finally resuspended in $0.5 \mathrm{ml}$. Two million Fluo-3-loaded spermatozoa were added to $1 \mathrm{ml}$ portions of TALP or TALP plus EGTA at room temperature. Calcium ionophore (A23187; Sigma) was added to a TALP-incubated sample for $20 \mathrm{~min}$ to induce the maximum calcium uptake. Propidium iodide ( $\mathrm{Pl} ; 2.5 \mu \mathrm{g} \mathrm{ml}^{-1}$ ) was added after treatments, and samples were analysed on the flow cytometer after 2 min. Changes in Fluo-3 staining patterns were measured as described by Harrison et al. (1993). Standard 'gates' for all treatments were set up around three distinct populations to delineate low intracellular $\mathrm{Ca}^{2+}$, high intracellular $\mathrm{Ca}^{2+}$ and non-viable spermatozoa. Gate settings were derived empirically, and live cells falling outside 'low' Fluo-3 staining ( 0 h) were considered 'high' Fluo-3-stained, that is, containing 'high' intracellular calcium concentrations.

\section{Detection of tyrosine-phosphorylated proteins by SDS- PAGE and western blotting}

Treated spermatozoa were prepared for SDS-PAGE essentially as described by Williams et al. (1997). Briefly, treated spermatozoa were pelleted by centrifugation at $600 \mathrm{~g}$ for $10 \mathrm{~min}$ and solubilized in $2 \times$ SDS sample buffer (SB; 125 mmol Tris-HCl I-1, pH 6.8, 4\% (w/v) SDS, 40\% $(\mathrm{v} / \mathrm{v})$ glycerol, $4.6 \mathrm{mmol}$ dithiothreitol (DTT) $\mathrm{I}^{-1}, 0.002 \%$ $(\mathrm{w} / \mathrm{v})$ bromophenol blue and phosphatase inhibitors (1 mmol phenylmethylsulphonyl fluoride (PMSF) $\mathrm{I}^{-1}, 1$ mmol $\mathrm{NaVO}_{4} \mathrm{I}^{-1}, 10 \mathrm{mmol} \mathrm{NaF} \mathrm{I}^{-1}$ ) and $4 \mu \mathrm{l}$ Sigma protease inhibitor cocktail $\mathrm{ml}^{-1}$ ). Samples were boiled for $5 \mathrm{~min}$ at $100^{\circ} \mathrm{C}$. Each lane was normalized to $1 \times 10^{6}$ spermatozoa per lane by counting cells five times before solubilization, to ensure equal protein loads. Samples were then subjected to
PAGE on $10 \%$ gels. Verification of protein loading was provided by staining gels with Coomassie blue stain. Coloured molecular weight standards (kaleidoscope; Bio-Rad, Hemel Hempstead) were run alongside all experimental samples. Proteins were transferred onto nitrocellulose membrane by wet blotting and blocked with $5 \%(\mathrm{w} / \mathrm{v})$ dried skimmed milk in TBS containing $0.05 \%$ Tween 20 (TTBS) for $1 \mathrm{~h}$ at room temperature. Blots were incubated with anti-phosphotyrosine antibody $4 \mathrm{G} 10$ (Upstate Biotechnology UK, Buckingham) at 1:1000 in 3\% $(\mathrm{w} / \mathrm{v}) \mathrm{BSA}$ in TTBS at $4^{\circ} \mathrm{C}$ overnight with agitation. After washing $(3 \times 5 \mathrm{~min}$; TBS $)$ blots were incubated with horseradish peroxidase (HRP; Chemicon International Ltd, Harrow) conjugated secondary antibody (1:5000) in TTBS-3\% BSA for $1 \mathrm{~h}$ at room temperature. The reaction was detected using chemiluminescence (ECL; Amersham, Little Chalfont) according to the manufacturer's instructions.

\section{Statistical analysis}

The data were expressed as means for live cells \pm SEM from eight boars. All measurements were calculated as percentages, which were transformed using arcsine transformations to normalize the data. One-way or two-way analysis of variance (ANOVA) was used for the statistical analysis of the data. The level of significance was considered $P<0.05$. Post hoc comparisons of least significant differences (LSDs) were evaluated between sample treatments.

\section{Results}

\section{Membrane status of cooled-re-warmed and incubated spermatozoa}

Spermatozoa incubated in TALP at $39^{\circ} \mathrm{C}$ (conditions that are known to support capacitation) and assessed at hourly intervals exhibited a progressive increase in the number of $B$ pattern cells and a commensurate decrease in the number of F pattern cells with time (Fig. 1a), whereas there was no change in spermatozoa incubated in PBS (data not shown). The proportion of AR pattern cells and non-viable cells also increased in the TALP medium (Fig. 1a), but not in PBS, over the $3 \mathrm{~h}$ period. Slow cooling below $22^{\circ} \mathrm{C}$ and re-warming to $39^{\circ} \mathrm{C}$ in PBS (Fig. 1b) revealed changes comparable to capacitation in vitro. A significant increase in the proportion of B pattern cells was detected after cooling to $15^{\circ} \mathrm{C}$ $(P<0.005)$ in comparison with samples incubated at 39 or $22^{\circ} \mathrm{C}$. The proportion of $\mathrm{B}$ pattern cells increased with declining temperatures, and was mirrored by a comparable decrease in the number of $F$ pattern cells. The number of $A R$ and dead cells did not change significantly.

The increase in the proportion of B pattern cells detected during cooling was only exhibited when samples were rewarmed to physiological temperatures $\left(39^{\circ} \mathrm{C}\right)$ (Fig. 2). Spermatozoa cooled to $4^{\circ} \mathrm{C}$ in PBS and re-warmed only to room temperature $\left(22^{\circ} \mathrm{C}\right)$ showed no increase in the number of B pattern cells compared with spermatozoa incubated for 
(a)

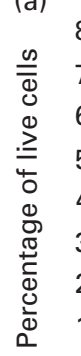

(b)

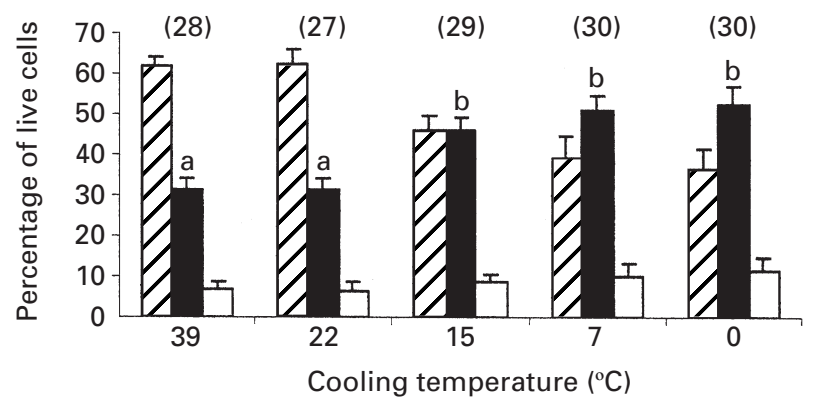

Fig. 1. (a) Chlortetracycline staining to detect the capacitation status of live boar spermatozoa incubated in Tyrode's complete medium (TALP) (capacitating medium) over $3 \mathrm{~h}$ (mean \pm SEM). (b) Chlortetracycline staining of live boar spermatozoa to reveal the effect of cooling temperature on the proportion of B pattern cells when spermatozoa were cooled and re-warmed for $10 \mathrm{~min}\left(39^{\circ} \mathrm{C}\right)$ in PBS (mean \pm SEM). Cooling temperature denotes the lowest temperature to which cells were cooled before re-warming. ${ }^{a b c}$ Different letters denote significant differences in the number of $B$ pattern cells between treatments $(P<0.05)$. Values in parentheses represent the proportion of dead spermatozoa for each treatment. $\boldsymbol{\nabla : F}$ pattern; $\square$ : B pattern; $\square$ : AR pattern.

$2 \mathrm{~h}$ at $39^{\circ} \mathrm{C}$. There was also no increase in the number of $\mathrm{B}$ pattern cells in spermatozoa maintained at room temperature and then re-warmed to $39^{\circ} \mathrm{C}$ (Fig. 2).

\section{Effects of cooling-re-warming and capacitation on membrane fluidity detected by MC540}

Preliminary experiments demonstrated that the addition or absence of $\mathrm{CaCl}_{2}$ had no effect on the uptake of MC540 in cooled or incubated samples, and $\mathrm{CaCl}_{2}$ was therefore omitted from all media (data not shown). Incubation in bicarbonate-containing Tyrode's medium induced a rapid and significant increase in membrane fluidity in control samples $(P<0.001)$, which had reached a maximum value by $5 \mathrm{~min}$ at $39^{\circ} \mathrm{C}$ (Fig. 3); no further increase was detected up to 60 min re-warming (data not shown). A similar but less pronounced result was evident for cooled spermatozoa in the presence of bicarbonate, but cooling and re-warming in the absence of bicarbonate did not result in changes in sperm membrane fluidity compared with control samples.

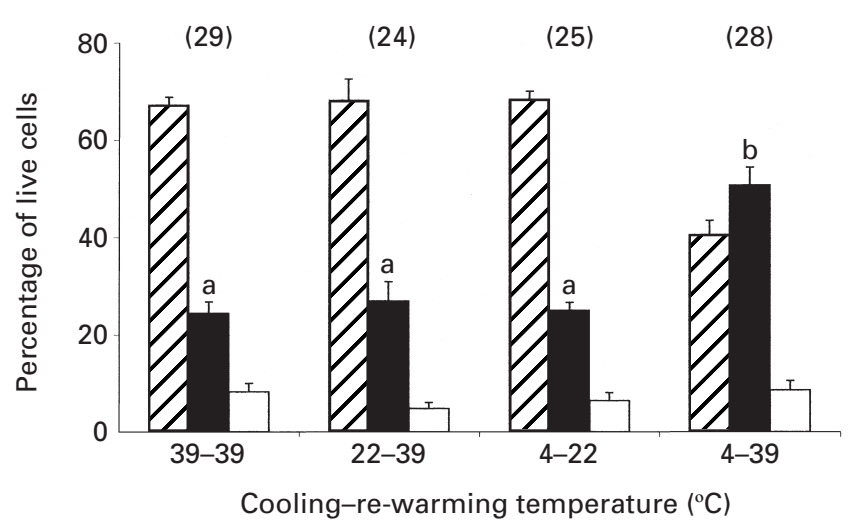

Fig. 2. Effect of cooling and re-warming on chlortetracycline staining in live boar spermatozoa diluted in PBS. Cooling temperature denotes the lowest temperature to which cells were cooled before re-warming. Re-warming temperature denotes the temperature to which cooled cells were re-warmed for $10 \mathrm{~min}$. ${ }^{a b}$ Different letters denote significant differences in the number of $B$ pattern cells between treatments $(P<0.05)$. Values in parentheses represent the proportion of dead spermatozoa for each treatment. $\nabla: F$ pattern; $\square$ : B pattern; $\square$ : AR pattern.

\section{Effects of cooling-re-warming and capacitation on intracellular calcium concentrations}

Incubation for $2 \mathrm{~h}$ at $39^{\circ} \mathrm{C}$ in TALP resulted in a significant increase in the proportion of cells with 'high' intracellular calcium concentrations in the sub-population of live cells compared with 0 h control samples $(P<0.001$; Fig. 4). The proportion of cells that had taken up $\mathrm{PI}$ also increased during the capacitation period. A high intracellular calcium concentration could be achieved in almost the entire live cell population of spermatozoa by stimulation with $\mathrm{Ca}^{2+}$ ionophore A23187 (Fig. 4).

Cooling spermatozoa in TALP and re-warming at $39^{\circ} \mathrm{C}$ for at least $1 \mathrm{~min}$ also resulted in an increase in the proportion of cells with 'high' intracellular calcium concentrations (Fig. 4). Cooling in TALP without re-warming resulted in a larger population of cells with a high calcium content than that seen with cooling and re-warming, which was more comparable to spermatozoa treated with $\mathrm{Ca}^{2+}$ ionophore (Fig. 4). Control samples maintained at $22^{\circ} \mathrm{C}$ for the duration of the cooling protocol and then incubated at $39^{\circ} \mathrm{C}$ for $10 \mathrm{~min}$ showed some increase in $\mathrm{Ca}^{2+}$ concentrations, but these increases were not comparable to spermatozoa that were cooled and re-warmed for the same period (Fig. 4). In the presence of EGTA, the calcium influx associated with spermatozoa cooled in TALP was not seen.

\section{Effect of cooling-re-warming and capacitation on tyrosine-phosphorylated proteins}

Whole cell extracts of washed boar spermatozoa $(0 \mathrm{~h}$ in TALP) displayed a number of constitutively tyrosinephosphorylated proteins at approximately $30 \mathrm{kDa}, 48 \mathrm{kDa}$, a 


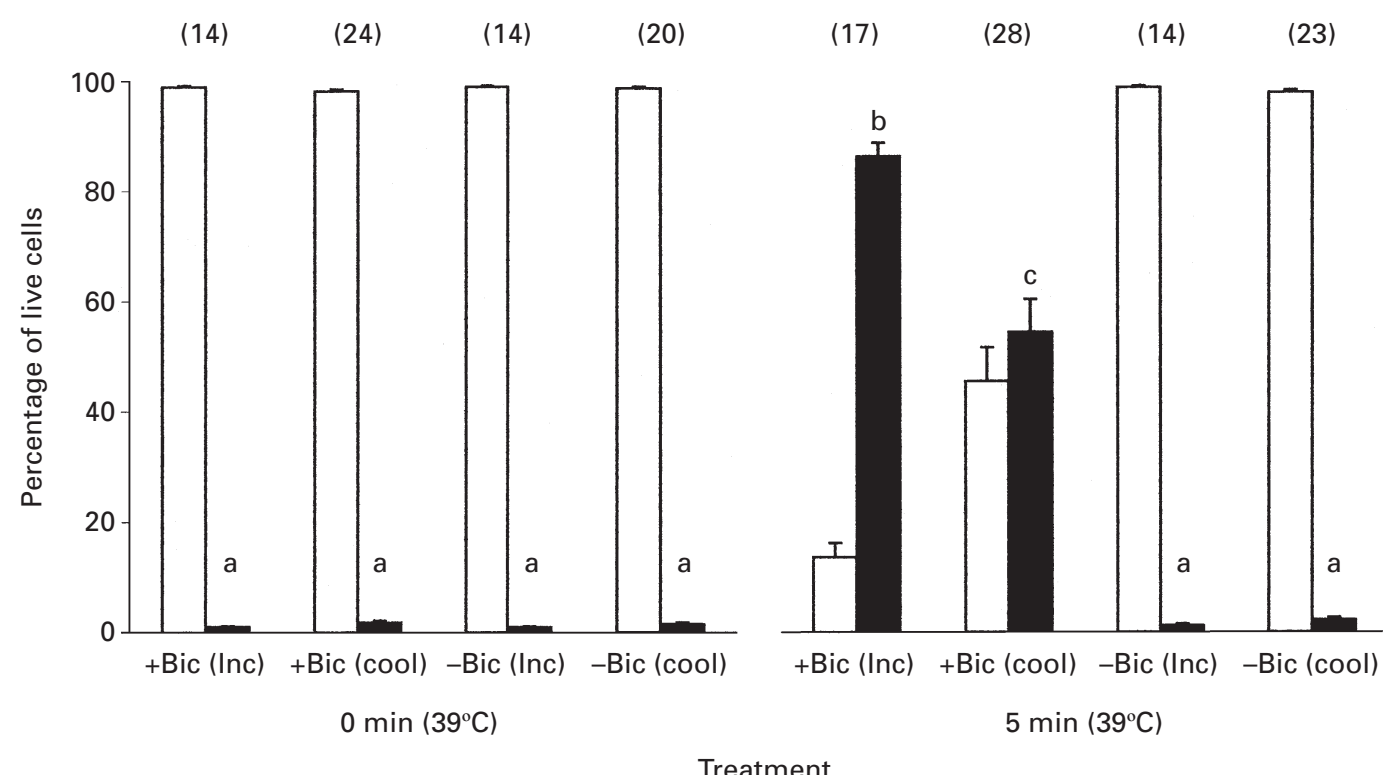

Fig. 3. Effect of bicarbonate (Bic) in Tyrode's medium and time of incubation (Inc) on the number of live boar spermatozoa exhibiting high merocyanine fluorescence staining (mean \pm SEM). Effects of both treatment and time were significant $(P<0.001)$. Values in parentheses represent the proportion of dead spermatozoa for each treatment. ${ }^{\text {abc }}$ Different letters denote significant differences in the percentage of spermatozoa exhibiting high merocyanine fluorescence between treatments $(P<0.05)$. $\square$ : Low merocyanine; $\mathbf{\square}$ : high merocyanine staining.

triplet of proteins between 50 and $55 \mathrm{kDa}$, and $63 \mathrm{kDa}$ (Fig. $5 a$, lane 1). Capacitated boar spermatozoa showed an increase in the number and expression of tyrosinephosphorylated proteins ranging from 33 to $220 \mathrm{kDa}$ (Fig. 5a, lane 3). This change was enhanced in the absence of calcium and with the addition of EGTA (Fig. 5a, lane 4). Spermatozoa that were cooled and re-warmed at $39^{\circ} \mathrm{C}$ for $10 \mathrm{~min}$ in TALP did not show an identical pattern of change to the TALPincubated samples, but did exhibit the increased phosphorylation of a $33 \mathrm{kDa}$ protein (p33; Fig. 5a, lane 5). The extent of $\mathrm{p} 33$ phosphorylation was more equivalent to that in ionophore-treated samples (Fig. 5a, lane 7) than to that in capacitated spermatozoa and was dependent on re-warming to $39^{\circ} \mathrm{C}$ for at least $10 \mathrm{~min}$ (Fig. 5b, lane 3). Continued incubation at $39^{\circ} \mathrm{C}$ after cooling resulted in a time-related increase in $\mathrm{p} 33$ phosphorylation, reaching a maximum value by $30 \mathrm{~min}$ (Fig. 5b). The intensity of p33 phosphorylation varied among individual boars and was inhibited or greatly reduced in the presence of EGTA (Fig. 5c).

\section{Discussion}

Capacitation is a sequential event involving numerous physiological changes such as changes in membrane fluidity (Harrison et al., 1996), increases in intracellular ion concentrations (Adeoya-Osiguwa and Fraser, 1993), and upregulation of cellular signalling pathways (Kalab et al., 1998). A comparison of in vitro capacitation and cooling of spermatozoa, using these several different markers of capacitation, reveals the extent of the similarities.

When bound to spermatozoa, the chlortetracycline molecule exhibits enhanced fluorescence that displays a characteristic distribution according to the capacitation state (Ward and Storey, 1984). The mechanism that determines the different chlortetracycline staining patterns is unclear; removal or masking of calcium-associated membrane proteins (Caswell and Hutchinson, 1971; Millman et al., 1980; Barboni, 1994) or the complexing of internalized chlortetracycline with $\mathrm{Ca}^{2+}$ (Tsien, 1989) may explain the patterns. Changes in calcium concentrations during capacitation and the acrosome reaction may account for the alterations in chlortetracycline staining patterns (Fraser and McDermott, 1992).

Capacitation in vitro was achieved by incubation of spermatozoa in TALP media at $39^{\circ} \mathrm{C}$ and did not occur if replaced with a non-capacitating simple medium such as PBS. The effects of cooling on changes in chlortetracycline patterns were therefore performed in PBS to ensure that changes detected were due to the reduction in temperature and not to the activating components of TALP media. The present study was in agreement with the results of previous studies (Watson, 1996; Cormier et al., 1997; Fuller and Whittingham, 1997; Maxwell and Johnson, 1997) in that chlortetracycline staining of cooled mammalian spermatozoa revealed similar membrane changes to capacitation. In addition, these changes were dependent on re-warming to 
(11)

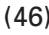

(30)

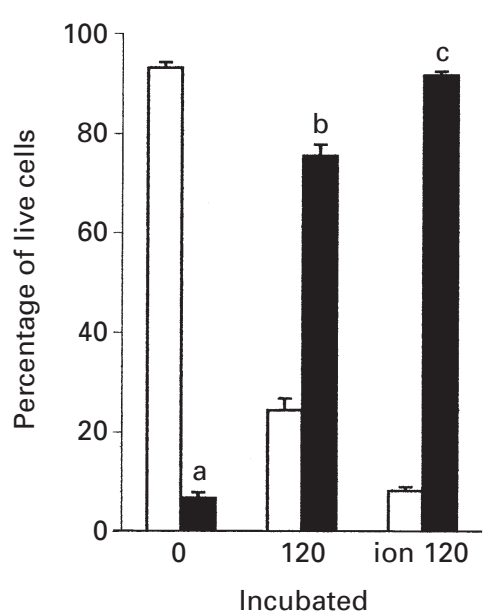

(24)

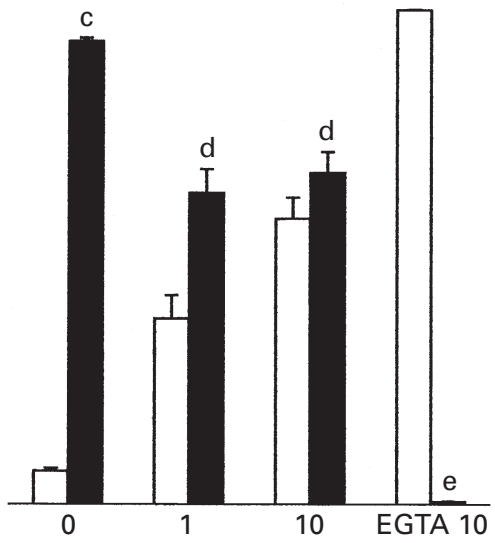

Cooled and re-warmed
(13)

(14)

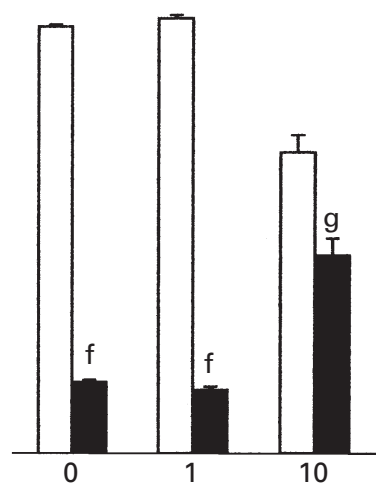

Ambient and incubated

Treatment

Fig. 4. Changes in intracellular free calcium concentrations in live boar spermatozoa (mean \pm SEM). Values in parentheses represent the proportion of dead spermatozoa for each treatment. All treatments were performed in Tyrode's complete medium (TALP), or TALP plus $1 \mathrm{mmol}$ EGTA $\mathrm{I}^{-1}$ or TALP plus $1 \mathrm{mmol}$ calcium ionophore $\mathrm{I}^{-1}$ (ion). Treatments were incubated at $39^{\circ} \mathrm{C}$ for 0,120 or $120 \mathrm{~min}$ plus calcium ionophore; cooled (to $5^{\circ} \mathrm{C}$ over $100 \mathrm{~min}$ ) and re-warmed at $39^{\circ} \mathrm{C}$ for 0,1 or $10 \mathrm{~min}$ in the presence of EGTA; or maintained at ambient temperature $(100 \mathrm{~min})$ and incubated for 0,1 or $10 \mathrm{~min}$ at $39^{\circ} \mathrm{C}$. ${ }^{\mathrm{a}-\mathrm{g}}$ Different letters denote significant differences in the percentage of spermatozoa exhibiting high calcium-Fluo-3 fluorescence between treatments $(P<0.05)$. $\square$ : Low Fluo-3 $\left(\mathrm{Ca}^{2+}\right)$; $\mathbf{\square}$ : high Fluo-3 $\left(\mathrm{Ca}^{2+}\right)$ staining.

$39^{\circ} \mathrm{C}$, indicating the involvement of enzymatic mechanisms, as re-warming to $22^{\circ} \mathrm{C}$ was insufficient to induce the capacitation-like change.

The manifestation of the capacitation-like effect in a larger proportion of the sperm population after cooling between 22 and $5^{\circ} \mathrm{C}$ (with re-warming to $39^{\circ} \mathrm{C}$ ) indicates that chlortetracycline staining patterns may be related to membrane lipid phase transitions that occur between these temperatures in boar spermatozoa (Drobnis et al., 1993). Although membrane alterations as a result of lateral phase transitions are considered to be reversible when returned to physiological temperatures (De Leeuw et al., 1990), Holt and North (1984) found that cooling-induced changes of some ram sperm membranes are only partially reversed when re-warmed. These modifications may then reflect lipid phase separation changes (exclusion of lipid species with lower transition temperatures in the liquid phase from areas that have already entered the gel phase, and clustering of membrane proteins) rather than mere cycles of phase transition (Drobnis et al., 1993). The physical reduction in plasma membrane sterols, for example cholesterol, as a result of cooling (Canvin and Buhr, 1989) may, in fact, mimic the removal of cholesterol by albumin experienced by spermatozoa undergoing capacitation (Go and Wolf, 1985; Visconti et al., 1999). Indeed, the movement of intramembranous proteins in cooled ram sperm membranes is apparent in the post-acrosomal region where staining with chlortetracycline shows that changes occur after coolingcapacitation (Holt and North, 1984). Therefore, it is plausible that a lower proportion of cholesterol in the postacrosomal region (Bradley et al., 1980) may predispose this domain to membrane alterations during cooling-induced phase transition and separation, and thus a capacitation-like appearance.

Modifications in the lipid content and organization of boar sperm plasma membranes result in changes to membrane fluidity when cooled (Canvin and Buhr, 1989). It was hypothesized that increases in membrane fluidity in cryopreserved sperm cell membranes (Hinkovska-Galcheva et al., 1989; Buhr et al., 1994) and sperm cell membranes capacitated in vitro (Harrison et al., 1996; Flesch et al., 1999) might also be evident after capacitation-like membrane changes occurring after hypothermic lipid phase changes. Changes in membrane architecture were detected using MC540, which inserts into the outer bilayer of loosely packed lipid membranes and exhibits greater fluorescence the more highly disordered the lipids are (Williamson et al., 1983). This probe has proven useful in detection of alterations in membrane fluidity during sperm capacitation (Harrison et al., 1996; Flesch et al.,1999).

In agreement with Harrison et al. (1996), the present study showed that incubation of fresh spermatozoa with bicarbonate-containing media induced a rapid increase in membrane fluidity. Unlike the protocol for chlortetracycline staining, in which capacitated control samples were incubated over a period of $3 \mathrm{~h}$, the increase in fluidity reached a maximum value after $5 \mathrm{~min}$ at $39^{\circ} \mathrm{C}$ (Harrison et al., 1996). Gadella and Harrison (2000) speculate that this 

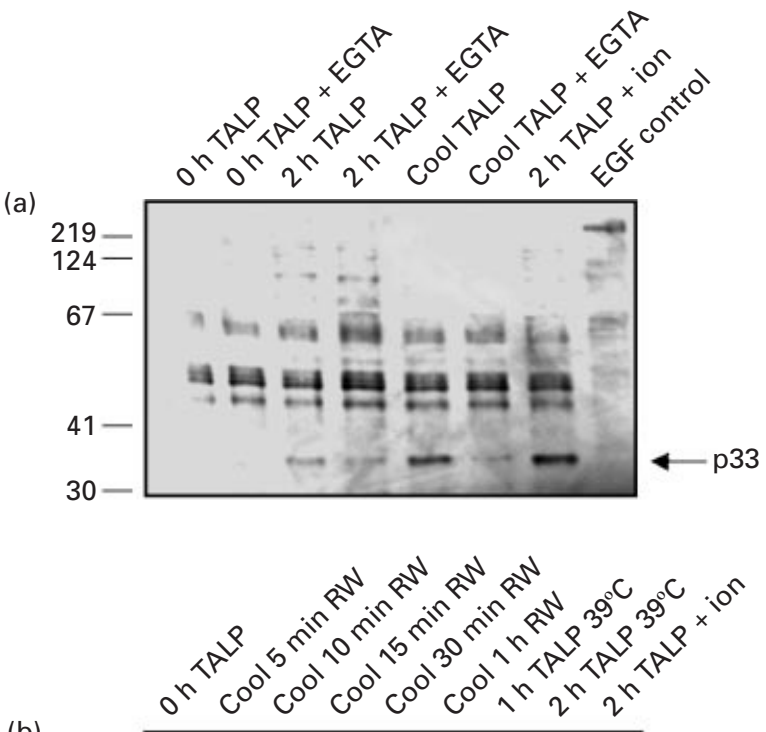

(b)

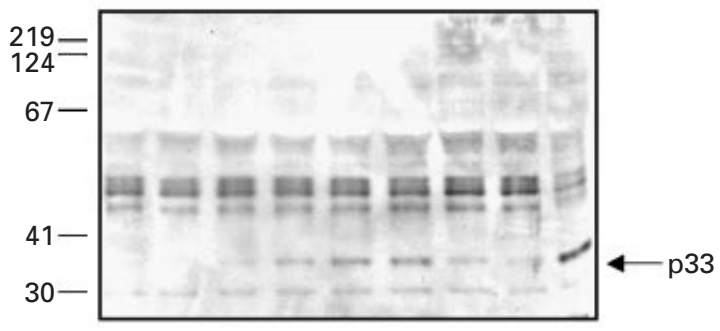

(c)

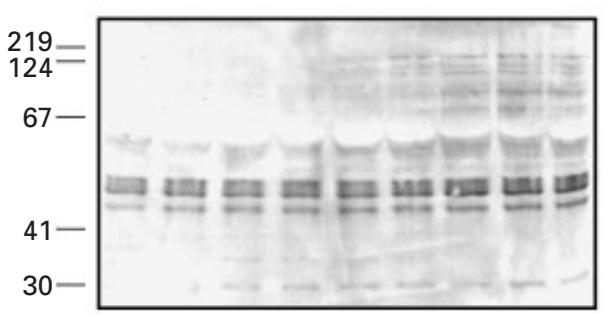

Fig. 5. (a) Example of cooled, re-warmed and capacitated tyrosine phosphorylation patterns in Tyrode's complete medium (TALP) \pm EGTA and capacitated plus calcium ionophore (+ ion) by western blotting of a single ejaculate of boar spermatozoa. Epidermal growth factor (EGF) control was a positive control for phosphotyrosine. Phosphorylation of a $33 \mathrm{kDa}$ protein (p33) was greater in cooled and re-warmed samples (lane 5) than it was in capacitated samples (lane 3) and was comparable to spermatozoa treated with calcium ionophore (lane 7). (b) Western blot stained with anti-phosphotyrosine antibodies to detect p33 tyrosine phosphorylation in spermatozoa cooled to $5^{\circ} \mathrm{C}$ and re-warmed (RW) to $39^{\circ} \mathrm{C}$ for various periods (5-60 min). p33 phosphorylation in cooled samples is dependent on subsequent re-warming time (pool of four boars). Spermatozoa capacitated for 1 or $2 \mathrm{~h}$ in TALP at $39^{\circ} \mathrm{C}$, or in the presence of ionophore (+ ion) are also shown. (c) Same treatments as in (b), but in the presence of $1 \mathrm{mmol}$ EGTA $\mathrm{I}^{-1}$. p33 phosphorylation was abolished by the addition of EGTA. The increase in capacitation-associated proteins (> $67 \mathrm{kDa}$; lanes 6 and 7) was enhanced by the presence of EGTA.

increase reflects a loss of membrane asymmetry and may serve as an early membrane priming event for albumin- mediated lipid changes (cholesterol efflux). As an adequate control, samples were incubated at room temperature in the appropriate medium (which was shown to have no effect), in parallel with cooled samples before they were transferred to a $39^{\circ} \mathrm{C}$ waterbath during the re-warming period. Cooling and re-warming in the absence of bicarbonate was not sufficient to induce changes in membrane fluidity as detected by merocyanine. Although increases in fluidity were not detected, this does not necessarily signify an absence of membrane alterations, but rather that they were not comparable to membrane changes associated with capacitation. However, spermatozoa cooled and re-warmed in the presence of bicarbonate exhibited a lesser membrane response compared with fresh spermatozoa incubated at $39^{\circ} \mathrm{C}$ under identical conditions. Therefore, cooling must have altered the membrane reaction to this bicarbonate stimulus. These alterations may be attributed to the changes in the lipid architecture alluded to above.

Perturbations of the plasma membrane during capacitation are associated with the increase in intracellular calcium concentrations (Harrison et al., 1993). Using the calcium-sensitive fluorescent probe Fluo-3, the authors detected large increases in intracellular calcium concentrations after incubation in TALP for $2 \mathrm{~h}$ at $39^{\circ} \mathrm{C}$. In contrast to the results reported by Bailey and Buhr (1995), in which chilled boar spermatozoa displayed an accumulation of intracellular calcium, the present study showed that boar spermatozoa cooled slowly and re-warmed in TALP media for $1-10 \mathrm{~min}$ at $39^{\circ} \mathrm{C}$ also exhibited increases in intracellular calcium concentrations that were similar to those of capacitated spermatozoa. Maintenance of spermatozoa in TALP at room temperature for $2 \mathrm{~h}$ followed by comparable incubations at $39^{\circ} \mathrm{C}$ did not result in the same increases in intracellular calcium, demonstrating that these changes were indeed the effects of cooling. Spermatozoa cooled, without re-warming, displayed larger increases in calcium that were more akin to those of cells that had been treated with calcium ionophore. It seems likely that re-warming at $39^{\circ} \mathrm{C}$ for as little as $1 \mathrm{~min}$ is sufficient to permit a subpopulation of live spermatozoa to undergo an enzymerelated recovery to normal, low intracellular calcium conditions, as a result of the activity of a membrane $\mathrm{Ca}^{2+}$ ATPase. In the present study, the inclusion of PI confirmed that this cellular influx and efflux of calcium was indeed occurring within the population of live cells. Previously, this had not been possible when detecting such changes using radioactively labelled calcium (Robertson et al., 1988); detection of changes in the whole cell population are likely to result in exaggerated intracellular calcium concentrations as a result of dysfunctional membranes of non-viable cells.

Although the stimulus that induces calcium uptake in cooled spermatozoa is quite different from that of capacitation, the underlying mechanisms may be quite similar. Increases in intracellular calcium detected during capacitation may simply occur as a result of changes in membrane permeability after fluidization of the plasma 
membrane, as shown by the effects of bicarbonate in vitro (as above) and in vivo (Snider and Clegg, 1975). If slow cooling of spermatozoa results in membrane rearrangements and consequent lipid packing faults (Drobnis et al., 1993), the effectiveness of the plasma membrane as a barrier is likely to be compromised. A specific change in permeability of calcium channels may also contribute to an increased calcium influx into the cell after cooling-induced alterations to the membrane (Watson, 1981).

An alternative theory accounting for the uptake of calcium during capacitation involves removal of specific cell surface components known as decapacitation factors upon entry into the female tract (Adeoya-Osiguwa and Fraser, 1993). Removal of decapacitation factors is thought to deactivate membrane-associated $\mathrm{Ca}^{2+}$ ATPases that usually maintain low sperm intracellular calcium concentrations by active pumping of the ions out of the cell. Temperatures below the optimum functional temperature of this enzyme are likely to inhibit or reduce its ability to export calcium ions, resulting in an increase in intracellular calcium. Therefore, the reinstatement of the activity of the $\mathrm{Ca}^{2+}$ ATPase pumps at $39^{\circ} \mathrm{C}$ may explain the reduction in high calcium content in spermatozoa that have been cooled and re-warmed, compared with spermatozoa that have only been cooled. Antibodies against a somatic cell $\mathrm{Ca}^{2+}$ ATPase have located this membrane-associated enzyme to the postacrosomal region of the mouse sperm head (Fraser, 1998). Therefore, it is possible that $\mathrm{Ca}^{2+}$ ATPases also serve a function in the calcium-related changes that occur during capacitation and cooling as detected by chlortetracycline staining.

Internalization of calcium is required for the completion of capacitation (Fraser and McDermott, 1992). The uptake of calcium during capacitation influences the status of cellular proteins, in particular tyrosine phosphorylations (Luconi et al., 1996; Leclerc et al., 1998). Authors have speculated that increases in intracellular calcium in cooled spermatozoa activate the same cell signalling pathways, and thus possess equivalent functionality (Cormier et al., 1997; Fuller and Whittingham, 1997; Maxwell and Johnson, 1997). As has been reported in several other mammalian species (Luconi et al., 1996; Kalab et al., 1998; Leclerc et al., 1998), the present study of boar spermatozoa demonstrated an increase in the number and expression of tyrosine-phosphorylated proteins (TPP) ranging from 33 to $220 \mathrm{kDa}$ after incubation in TALP media containing $2 \mathrm{mmol} \mathrm{CaCl}{ }_{2} \mathrm{I}^{-1}$. Paradoxically, although capacitation is associated with the increase in intracellular calcium concentrations, enhanced phosphorylation of many TPP (between 60 and $200 \mathrm{kDa}$ ) occurred in its absence (plus EGTA), and phosphorylation decreased in the presence of calcium ionophore (Kalab et al., 1998), signifying a fine balance between kinase and phosphatase activity. However, not all changes in all tyrosine-phosphorylated proteins during capacitation followed this pattern. The increase in phosphorylation of a $33 \mathrm{kDa}$ protein during capacitation was enhanced greatly by the addition of calcium ionophore. This protein may be comparable to the $33 \mathrm{kDa}$ protein with increased tyrosine phosphorylation detected by Flesch et al. (1999) in capacitated and acrosome-reacted boar spermatozoa, and the $32 \mathrm{kDa}$ tyrosine-phosphorylated peripheral membrane protein, detected in capacitated pig spermatozoa by Tardif et al. (2000). The discrepancy in size (Tardif et al., 2000) may result from minor differences between laboratory protocols.

The presence of TPP in bull (Cormier et al., 2000) and hamster $(\mathrm{Si}, 1999)$ spermatozoa can be modulated after cryopreservation or cooling below physiological temperatures, respectively. However, cooling to $5^{\circ} \mathrm{C}$ (and rewarming) in TALP was insufficient to induce the phosphorylation of those proteins $(>67 \mathrm{kDa})$ detected during capacitation, indicating that alternative intracellular mechanisms are governing these changes. Nevertheless, the discovery of a calcium-dependent $33 \mathrm{kDa}$ tyrosinephosphorylated protein in cooled and re-warmed samples, which was comparable to calcium ionophore-treated samples, does indicate that influx of calcium is having some ongoing effects on signalling pathways. The necessity for rewarming to detect the expression of this protein, again points to the involvement of calcium-dependent enzymerelated events in the onset of the capacitation-like changes.

In conclusion, this study has shown that spermatozoa cooled to $5^{\circ} \mathrm{C}$ display some characteristics of capacitation, showing similar membrane changes and increases in intracellular calcium concentrations. However, the merocyanine experiments and tyrosine phosphorylation data show, for the first time, that this process is not completely mirrored, but rather involves alternative routes of activation that arrive at a similar endpoint: destabilized membranes that will readily undergo an acrosome reaction. A speculative sequence of events during and after cooling and re-warming might involve the rearrangement of lipid membrane domains, resulting in an increase in membrane permeability and thus influx of extracellular ions such as $\mathrm{Ca}^{2+}$. Once inside the cell, the increased $\mathrm{Ca}^{2+}$ concentrations may be sufficient to initiate further sperm development. In all the techniques used, the detection of cooling-related changes appears to be largely influenced by re-warming to $39^{\circ} \mathrm{C}$, indicating that these alterations are under enzymic control. Moreover, evidence from Fluo-3 staining and western blotting indicates that cooling bypasses the need for capacitation, rather than inducing a state of capacitation, as spermatozoa express certain characteristics more redolent of cells undergoing acrosomal exocytosis. In this context, Clarke and Johnson (1987) reported that cryopreserved spermatozoa had a high proportion of acrosome-reacted cells, implying that the cryopreservation process had induced these changes.

Given the recognized compromised fertility of cryopreserved spermatozoa, the above data offer a contributory explanation. Apart from the fact that about $50 \%$ of spermatozoa do not survive cryopreservation, and that motility in the surviving population is poorer than it is in fresh spermatozoa, it seems that the readiness with which 
cooled and re-warmed spermatozoa undergo the acrosome reaction may also limit their fertilizing ability in vivo. After insemination, spermatozoa must survive long enough to traverse the reproductive tract and colonize the oviduct in order to fertilize. If their lifespan is reduced because their membranes are rendered unstable by the cooling and rewarming process, spermatozoa may not remain viable long enough to reach the site of fertilization. Moreover, if an acrosome reaction occurs too soon, the spermatozoa will be unable to fertilize, even if they survive. Thus, cooled and rewarmed spermatozoa are unlikely to display normal fertility if inseminated into the lower female reproductive tract. A fuller discussion of this is to be found in Watson (1995).

The characterization of some of these cooling-induced mechanisms now provides opportunities to target these specific processes to achieve more successful cryopreservation of boar semen.

The authors would like to thank Ros Elliott for advice, and Shanta Cariese and John Millar for their technical assistance. The Pig Improvement Company (PIC) UK provided financial support and donated the boar semen. C. E. Green was the recipient of a CASE award from Ministry of Agriculture, Fisheries and Food (MAFF) and the Pig Improvement Company (PIC) UK.

\section{References}

Adeoya-Osiguwa SA and Fraser LR (1993) A biphasic pattern of ${ }^{45} \mathrm{Ca}^{2+}$ uptake by mouse spermatozoa in vitro correlates with changing functional potential Journal of Reproduction and Fertility 99 187-194

Bailey J and Buhr MM (1995) Regulation of internal $\mathrm{Ca}^{2+}$ by chilled bull and boar spermatozoa Cryobiology 32 259-269

Barboni B (1994) Methods for the assessment of capacitation Zygote 2 367-369

Bradley MP, Rayns DG and Forrester IT (1980) Effects of filipin, digitonin and polymixin $B$ on plasma membrane of ram spermatozoa: an EM study Archives of Andrology 4 195-204

Buhr MM, Curtis EF and Kakuda NS (1994) Composition and behaviour of head membrane lipids of fresh and cryopreserved boar sperm Cryobiology 31 224-238

Canvin AT and Buhr MM (1989) Effect of temperature on the fluidity of boar sperm membranes Journal of Reproduction and Fertility 85 533-540

Caswell AH and Hutchinson JD (1971) Visualization of membrane cations by fluorescent staining technique Biochemical and Biophysical Research Communications 42 43-49

Clarke RN and Johnson LA (1987) Effect of liquid nitrogen storage and cryopreservation of boar spermatozoa on acrosomal integrity and the penetration of zona-free hamster ova in vitro. Gamete Research $\mathbf{6}$ 980-984

Cormier N, Sirard MA and Bailey JL (1997) Premature capacitation of bovine spermatozoa is initiated by cryopreservation Journal of Andrology 18 461-467

Cormier N, Berube B and Bailey JL (2000) A 56-kDa phosphotyrosinecontaining protein is associated with capacitation of bovine sperm induced by heparin or cryopreservation Biology of Reproduction Supplement 62136 (Abstract)

De Leeuw FE, Chen HC, Colenbrander B and Verkleij AJ (1990) Coldinduced ultrastructural changes in bull and boar sperm plasma membranes Cryobiology 27 171-183

Drobnis EZ, Crowe LM, Berger T, Anchordoguy TJ, Overstreet JW and Crowe JH (1993) Cold shock damage is due to lipid phase transitions in cell membranes: a demonstration using sperm as a model Journal of Experimental Zoology 265 432-437
Flesch FM, Colenbrander B, van Golde LMG and Gadella BM (1999) Capacitation induces tyrosine phosphorylation of proteins in the boar sperm plasma membrane Biochemical and Biophysical Research Communications 262 787-792

Fraser LR (1998) Interactions between a decapacitation factor and mouse spermatozoa appear to involve fucose residues and a GPI-anchored receptor Molecular Reproduction and Development 51 193-202

Fraser LR and McDermott CA (1992) $\mathrm{Ca}^{2+}$-related changes in the mouse sperm capacitation state: a possible role for $\mathrm{Ca}^{2+}$-ATPase Journal of Reproduction and Fertility 96 363-377

Fuller SJ and Whittingham DG (1996) Effect of cooling mouse spermatozoa to $4^{\circ} \mathrm{C}$ on fertilization and embryonic development Journal of Reproduction and Fertility 108 139-145

Fuller SJ and Whittingham DG (1997) Capacitation-like changes occur in mouse spermatozoa cooled to low temperatures Molecular Reproduction and Development 46 313-324

Gadella BM and Harrison RAP (2000) The capacitating agent bicarbonate induces protein kinase A-dependent changes in phospholipid transbilayer behavior in the sperm plasma membrane Development 127 $2407-2420$

Gillan L, Skovgold K, Watson PF, Evans G and Maxwell WM (1999) Fate and functional integrity of fresh and frozen-thawed ram spermatozoa following intrauterine insemination Reproduction, Fertility and Development 11 309-315

Go KJ and Wolf DP (1985) Albumin-mediated changes in sperm sterol content during capacitation Biology of Reproduction 32 145-153

Harrison RAP, Mairet B and Miller NGA (1993) Flow cytometric studies of bicarbonate-mediated $\mathrm{Ca}^{2+}$ influx in boar sperm populations Molecular Reproduction and Development 35 197-208

Harrison RAP, Ashworth PJC and Miller NGA (1996) Bicarbonate/ $\mathrm{CO}_{2}$, an effector of capacitation, induces a rapid and reversible change in the lipid architecture of boar sperm plasma membranes Molecular Reproduction and Development 45 378-391

Hinkovska-Galcheva V, Petkova D and Koumanov K (1989) Changes in the phospholipid composition and phospholipid asymmetry of ram sperm plasma membranes after cryopreservation Cryobiology 26 70-75

Holt WV and North RD (1984) Partially irreversible cold-induced lipid phase transitions in mammalian sperm plasma membrane domains: freeze-fracture study Journal of Experimental Zoology 230 473-483

Johnson LA (1985) Fertility results using frozen boar semen: 1970-1985. In Deep Freezing of Boar Semen pp 199-222 Eds LA Johnson and K Larsson. Swedish University of Agricultural Sciences and USDA, Uppsala

Kalab P, Peknicova J, Geussova G and Moos J (1998) Regulation of protein tyrosine phosphorylation in boar sperm through a cAMP-dependent pathway Molecular Reproduction and Development 51 304-314

Leclerc P, de Lamirande E and Gagon C (1996) Cyclic adenosine 3', 5'monophosphate-dependent regulation of protein tyrosine phosphorylation in relation to human sperm capacitation and motility Biology of Reproduction 55 684-692

Leclerc P, de Lamirande E and Gagnon C (1998) Interaction between $\mathrm{Ca}^{2+}$, cyclic 3',5'-adenosine monophosphate, the superoxide anion, and tyrosine phosphorylation pathways in the regulation of human sperm capacitation Journal of Andrology 19 434-443

Luconi M, Krausz C, Forti G and Baldi E (1996) Extracellular calcium negatively modulates tyrosine phosphorylation and tyrosine kinase activity during capacitation of human spermatozoa Biology of Reproduction 55 207-216

Maxwell WM and Johnson LA (1997) Chlortetracycline analysis of boar spermatozoa after incubation, flow cytometric sorting, cooling, or cryopreservation Molecular Reproduction and Development 46 408-418

Maxwell WM, Evans G, Rhodes SL, Hillard MA and Bindon BM (1993) Fertility of superovulated ewes after intrauterine or oviducal insemination with low numbers of fresh or frozen-thawed spermatozoa Reproduction, Fertility and Development 5 57-63

Millman MS, Caswell AH and Haynes DH (1980) Kinetics of chlortetracycline permeation in fragmented, ATPase-rich sarcoplasmic reticulum Membrane Biochemistry 3 291-315

Parrish JJ and Foote RH (1986) Fertility of cooled and frozen rabbit sperm 
measured by competitive fertilization Biology of Reproduction 35 253-257

Parrish JJ, Susko-Parrish J, Winer MA and First NL (1988) Capacitation of bovine sperm by heparin Biology of Reproduction 38 1171-1180

Polge C, Salamon S and Wilmut I (1970) Fertilizing capacity of frozen boar semen following surgical insemination Veterinary Record 87 424-428

Pursel VG and Johnson LA (1975) Freezing of boar spermatozoa; fertilizing capacity with concentrated semen and a new thawing procedure Journal of Animal Science 40 99-102

Robertson L, Watson PF and Plummer JM (1988) Prior incubation reduces calcium uptake and membrane disruption in boar spermatozoa subjected to cold shock CryoLetters 9 286-293

Si Y (1999) Hyperactivation of hamster sperm motility by temperaturedependent tyrosine phosphorylation of an $80-\mathrm{kDa}$ protein Biology of Reproduction 61 247-252

Snider DR and Clegg ED (1975) Alteration of phospholipids in porcine spermatozoa during in vivo uterus and oviduct incubation Journal of Animal Science 40 269-274

Tardif S, Dube C and Bailey JL (2000) A 32-kDa tyrosine-phosphorylated protein with tyrosine kinase activity associated with capacitation of porcine sperm Biology of Reproduction Supplement 62138 (Abstract)

Tsien RY (1989) Fluorescent indicators of ion concentrations. In Fluorescent Microscopy of Living Cells in Culture Part B: Quantitative Fluorescent Microscopy - Imaging and Spectroscopy, Methods in Cell Biology Vol. 30, pp 127-156 Eds DL Taylor and Y-L Wang. Academic Press, New York

Visconti PE, Ning X, Fornes MW, Alvarez JG, Stein P, Connors SA and Kopf GS (1999) Cholesterol efflux-mediated signal transduction in mammalian sperm: cholesterol release signals an increase in protein tyrosine phosphorylation during mouse sperm capacitation Developmental Biology 214 429-443

Waberski D, Weitze KF, Gleumes T, Schwartz M, Willmen T and Petzoldt $\mathbf{R}$ (1994) Effect of time of insemination relative to ovulation on fertility with liquid and frozen boar semen Theriogenology 42 831-840
Wang WH, Abeydeera LR, Fraser LR and Niwa K (1995) Functional analysis using chlortetracycline fluorescence and in vitro fertilization of frozenthawed ejaculated boar spermatozoa incubated in a protein free chemically defined medium Journal of Reproduction and Fertility $\mathbf{1 0 4}$ 305-313

Ward CR and Storey BT (1984) Determination of the time course of capacitation in mouse spermatozoa using a chlortetracycline fluorescence assay Developmental Biology 104 287-296

Watson PF (1979) The preservation of semen in mammals. In Oxford Reviews of Reproductive Biology Vol. 1 pp 283-350 Ed. CA Finn. Oxford University Press, Oxford

Watson PF (1981) The effects of cold shock on sperm cell membranes. In Effects of Low Temperatures on Biological Membranes pp 189-218 Eds G) Morris and A Clarke. Academic Press, London

Watson PF (1990) Artificial insemination and the preservation of semen. In Marshall's Physiology of Reproduction 4th Edn Vol. II pp 747-869 Ed. GE Lamming. Churchill Livingstone, London

Watson PF (1995) Recent developments and concepts in the cryopreservation of spermatozoa and the assessment of their postthawing function Reproduction, Fertility and Development 7 871-891

Watson PF (1996) Cooling of spermatozoa and fertilizing capacity Reproduction in Domestic Animals 31 135-140

Williams CD, Linch DC, Watts MJ and Thomas NS (1997) Characterization of cell cycle status and E2F complexes in mobilized CD34+ cells before and after cytokine stimulation Blood 90 194-203

Williamson P, Mattocks K and Schlegel RA (1983) Merocyanine 540, a fluorescent probe sensitive to lipid packing Biochimica et Biophysica Acta 732 387-393

Received 26 April 2001

First decision 27 July 2001.

Accepted 29 August 2001. 